Www.jmscr.igmpublication.org 倞
Impact Factor 3.79

ISSN (e)-2347-176x

crossref DOI: http://dx.doi.org/10.18535/jmscr/v3i9.50

\title{
Hysteroscopic Removal of Intrauterine Fetal Bones: Indian Scenario
}

\author{
Authors \\ Dr Shailesh Jain ${ }^{1}$, Dr Rakesh P. Khuteta ${ }^{2}$, Dr Sapna Shrivastava ${ }^{3}$ \\ ${ }^{1}$ Assistant Professor (Obs and Gynae), Jaipuriya Hospital (RUHS CMS), Jaipur (Rajasthan)-302018 \\ Email: Jainshailesh2001@ gmail.com, Mobile no.9414238568 \\ ${ }^{2}$ Professor and Head (Obs and Gynae), Jaipuriya Hospital (RUHS CMS), Jaipur (Rajasthan)-302018 \\ Email: Khuteta@hotmail.com, Mobileno.9829056919 \\ ${ }^{3}$ Senior Demonstrator (Pathology), Jaipuriya Hospital (RUHS CMS), Jaipur (Rajasthan)-302018 \\ Email: sapnashrivastava26@gmail.com, Mobile no.9414265962
}

\begin{abstract}
The incidence of retained fetal bones is unknown. Most of the women present with secondary infertility and history of previous abortion. Previously, these were removed by dilatation and removal with ovum forceps but now a days hysteroscopy has given new dimensions to such procedures. Hysteroscopy is widely used in such 'look and remove' procedures like endometrial polyp removal, resection septum, hysteroscopy guided biopsy, synechiolysis, removal of intra-uterine fetal bones etc.
\end{abstract}

Keywords: Retained intrauterine fetal bones, hysteroscopy

\section{Case Report}

Mrs. X, 30 year old, P2L2 came to our OPD with secondary infertility. She had two female children, full term normal vaginal delivery (10 and 8 year old). The couples were trying to conceive since last 5 years. Her menstrual cycle was normal with regular flow. Husband had normal semen analysis. Her TSH, prolactin and other investigations were normal. USG showed calcification in uterine cavity. HSG showed bilateral patent tubes with calcific foci uterine cavity. On hysteroscopy, bony pieces were seen which were removed and sent for histopathological confirmation. After procedure, they revealed a 4 month induced termination of pregnancy at peripheral village 5 years back as it was a female fetus diagnosed by ultrasound. Woman was kept on estrogen and progesterone combination for 2 months. She was in regular follow up till she conceived after 6 months. On the very first antenatal visit, couple asked me.. "Sir, will you diagnose this time that it is male or female in third month?" and I was speechless....

\section{Discussion}

Endometrial osseous metaplasia ${ }^{[5]}$ is a rare clinical entity with the presence of mature or immature bone in the endometrium. Nearly 80 cases have been reported in the world literature including around nine cases from India. In most of the reported cases, ossification was followed by an abortion and patients presented with infertility. ${ }^{[1-5]}$ 


\section{JMSCR Vol||3||Issue |99||Page 7611-7613||September}

Endometritis ossificans also reported in a post menopausal lady 72 years old. She also had a history of abortion in her reproductive years ${ }^{[3]}$. In India, endometrial tuberculosis should be ruled out as it can cause infertility as well as calcification and subsequent ossification ${ }^{[4]}$ In India, sex ratio is decreasing. People have in their minds that only a male child carries forward their family name. Thus, Incidence of female feticide is on an increase. In 2013, Abortions reported were 661,353. Though government of India is fighting against this by implementing various acts like PCPNDT and various schemes for daughters born but the dilemma is the false belief of general population. This case report emphasizes on a very important issue in Indian subcontinent.

Education and change in attitude of people will play a role in reducing such cases, otherwise number of such cases will increase.



Image 1: fetal bones

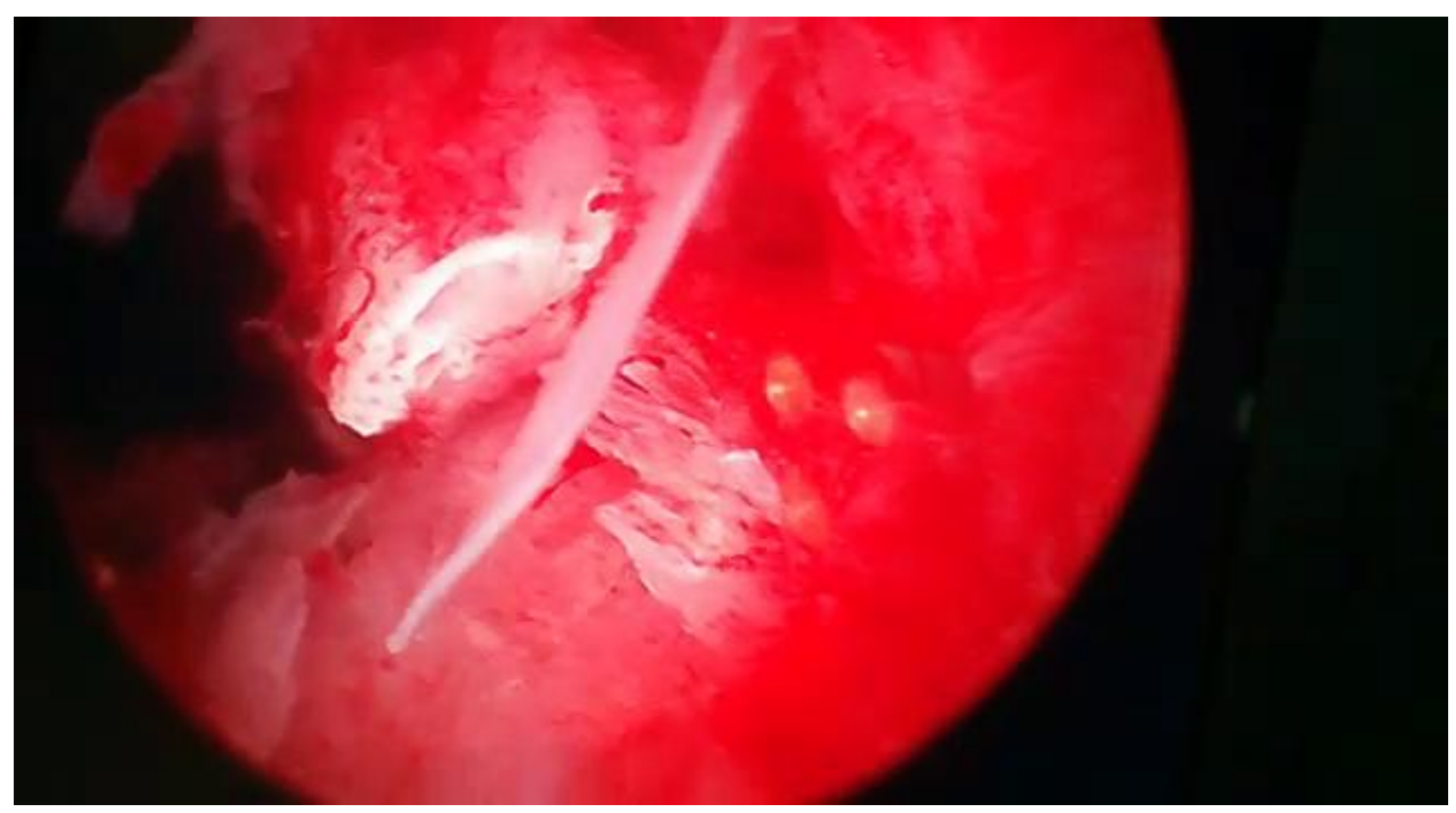

Image 2: fetal bones 


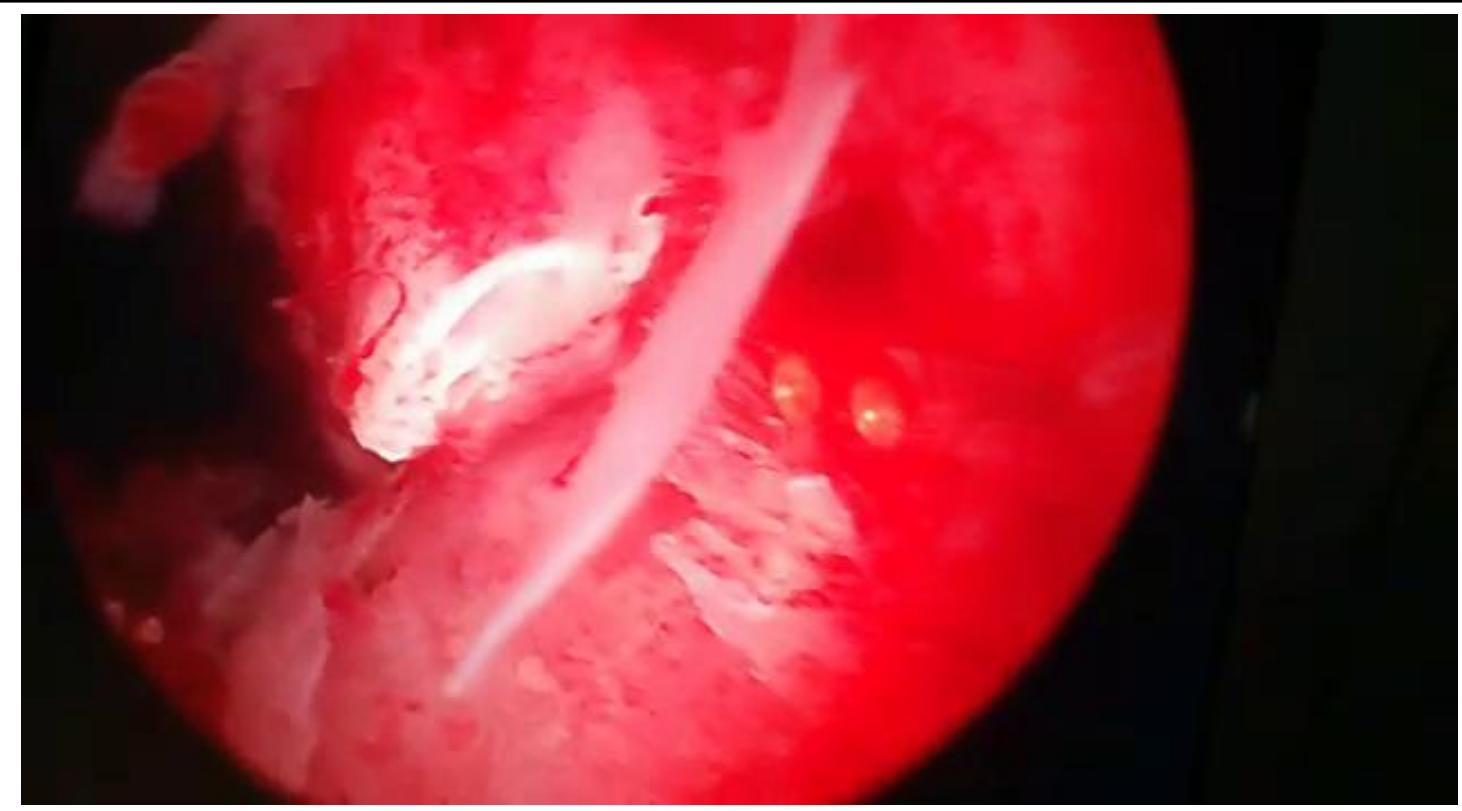

Image 3. fetal bones

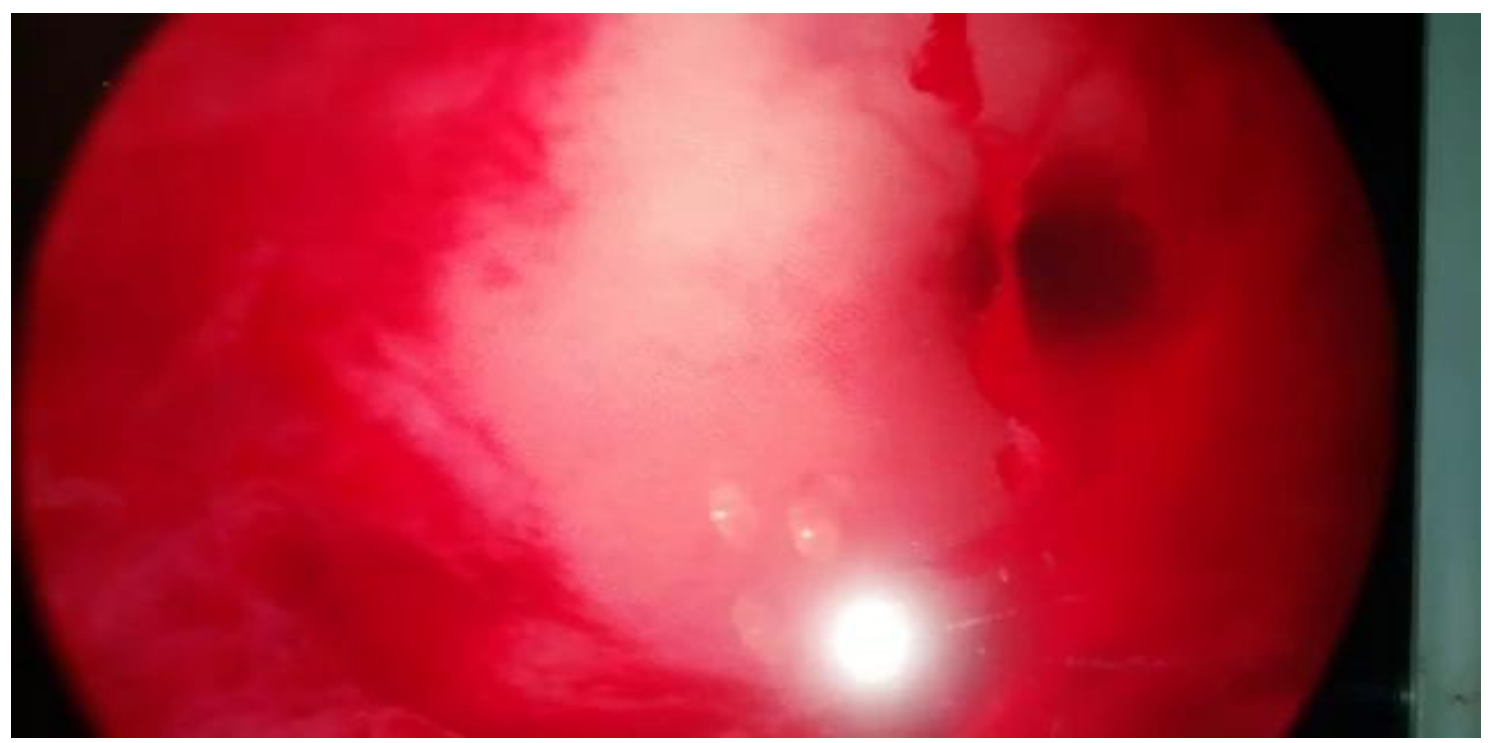

Image 4. Ostia visible after removal of bones

\section{References}

1. Hsu C. Endometrial ossification. $\mathrm{Br} \mathrm{J}$ Obstet Gynaecol. 1975;82:836-9.

2. Dutt S. Endometrial ossification associated with secondary infertility. $\mathrm{Br} \mathrm{J}$ Obstet Gynaecol. 1978;85:787-9.

3. Shimizu M, Nakayama M. Endometrial ossification in a postmenopausal woman. J Clin Pathol.1997;50:171-2.
4. Acharya U, Pinion SB, Parkin DE, Hamilton MP. Osseous metaplasia of the endometrium treated by hysteroscopic resection. $\mathrm{Br} \quad \mathrm{J} \quad$ Obstet Gynaecol. 1993;100:391-2.

5. T Umashankar, Shobhana Patted, RS Handigund. Endometrial osseous metaplasia: Clinicopathological study of a case and literature review. J Hum Reprod Sci. 2010 May-Aug; 3(2): 102-104. 